\title{
Comparative Study of Reciproc and Manual systems with Solvent in Root Canal Retreatment using Scan Electron Microscope
}

\author{
Amr M Eldemerdash ${ }^{1}$, Hayam Y Hassan ${ }^{2 *}$, Salma H El Ashry ${ }^{3}$ \\ ${ }^{1}$ Resident dentist in Endodontic Department, Faculty of Dentistry, Suez Canal University, Ismailia, Egypt \\ ${ }^{2}$ Associate Professor of Endodontic, Faculty of Dentistry, Suez Canal University, Ismailia, Egypt \\ ${ }^{3}$ Professor of Endodontic, Faculty of Dentistry, Ain Shams University, Cairo, Egypt
}

*Corresponding Author: Hayam Y Hassan, Associate Professor of Endodontic, Faculty of Dentistry, Suez Canal University, Ismailia, Egypt.

Received: July 31, 2019; Published: August 30, 2019

DOI: $10.31080 /$ ASDS.2019.03.0631

\begin{abstract}
Aim: The purpose of this study is to evaluate the efficacy of Reciproc and manual systems with and without solvent for removing Real-Seal SE obturating system and Gutta-percha with resin sealer in Root Canal Retreatment using SEM.

Material and Method: Eighty extracted mandibular premolars having one root canal were distributed into two groups stated to the obturation systems (Real-Seal SE obturating system and Gutta-percha with resin sealer) used. Then subdivided into two subgroups according to the method of obturating material removal (Reciproc and manual technique). Further subdivided into two classes by using solvent or not. Roots were separated in bacco-lingual direction into two equal halves then analyzed using Environmental Scan Electron Microscope (SEM) at the cervical, middle and apical parts.

Results: Reciproc system as retreatment instrument give best result than manual instruments in removing both obturating material used (Real-Seal SE system and Gutta-Percha) and this was statistically significant. Without using solvent give the result better than using solvent in removing both obturating material used (Real-Seal SE system and Gutta-Percha) and this was statistically significant. Apical region recorded highest debris mean value followed by middle region while the lowest mean value recorded cervically and this was statistically significant.

Conclusion: Reciproc system was more efficient than manual instruments in removal of root canal obturating materials in endodontic retreatment.
\end{abstract}

Keywords: Reciproc; Real-Seal SE; Retreatment; Scan Electron Microscope

\section{Introduction}

The main goal of endodontic treatment is to decrease the microbes inside the root canal by chemo-mechanical preparation, avoid re-infection and initiate periapical healing by hermetically sealing the root canal space [1]. Failure of endodontic treatment is the outcome of micro-organisms preserving in the root canal system [2]. Non-surgical retreatment would be the most conservative treatment of choice [3]. Retreatment is the removal of the obturating material to enable effective cleaning and shaping of the root canal system prior to refilling [4]. Gutta-percha is most standard used for obturation but, it does not adhere to the sealers or the dentine [5]. Real-Seal SE obturating system has introduced and is able to produce a monoblock inside the canal space, and the resulting complex could bonded to the root dentine by the resin-based primer [6]. Several instruments used to remove the root obturating material from the root canal system, as well as the 


\section{Material and Method}

Eighty recently extracted sound permanent human singlerooted mandibular premolar teeth were collected, cleaned and stored. Crowns of all teeth were removed by a diamond disk and the root length was standardized to approximately $17 \mathrm{~mm}$. Working length was measured by using k-file \#10 visually at one $\mathrm{mm}$ of the apical foramen.

\section{Root canal preparation}

The root canals of all teeth were prepared with Gates-Glidden drills size 4, 3 and 2 was used to prepare the cervical and middle thirds of the root canal. The apical thirds were prepared till k-file size 40 using the balanced force technique. $1 \mathrm{ml}$ of freshly prepared $1.3 \%$ sodium hypochlorite Irrigation was used after each file, followed by a flush of $5 \mathrm{ml}$ of $17 \%$ EDTA for $1 \mathrm{~min}$ to remove the smear layer.

\section{Grouping of samples}

The 80 specimens were divided into 2 equal main groups $(n=40)$ according to obturating material. Group A: the root canals were obturated using Real-Seal SE obturating system (Sybronendo, West collins Avenue, Orange, CA U.S.A). Real-Seal SE primer was applied and coated the inside walls of each root canal according to manufacturer's instructions using a paper point. Real-Seal sealer mixed on a mixing pad and canals coated completely using lentulo spiral (Dentsply, Maillefer, Ballaigues, Switzerland) and any excess material was removed. Real-Seal points \#40 taper 0.02 master cones and accessory points were coated with sealer. Real-Seal points were seated to the working length. Obturation completed using lateral condensation technique then curing done with light cure for 40 seconds. Group B: the root canals were obturated using gutta percha points with ADSEAL resin sealer (Meta Biomed, Cheongju, South Korea) according to manufacturer's instructions.

Then each group was subdivided into two subgroups $(n=20)$ according to the method of obturating material removal. The first subgroup of each group $A_{1}$ and $B_{1}$ the obturating material was removed using Reciproc file \#40 (VDW, GmbH, Munich, Germany). The second subgroup of each group $A_{2}$ and $B_{2}$ the obturating material was removed using Gates Glidden \# 4, 3, 2 and H-file\#40.

Then, each subgroup subdivided into two classes $(n=10)$ : The first class of each subgroup $\left(\mathrm{A}_{1 \mathrm{a}}, \mathrm{A}_{2 \mathrm{a}}, \mathrm{B}_{1 \mathrm{a}}\right.$ and $\left.\mathrm{B}_{2 \mathrm{a}}\right)$ the obturating material was removed using the removal in-combination with chloroform (ADWIC, Com. Qaliubiya, Egypt) as a solvent. The second class of each subgroup $\left(A_{1 b}, A_{2 b}, B_{1 b}\right.$ and $\left.B_{2 b}\right)$ the obturating material was removed using the removal systems without using any solvent.

\section{Retreatment technique}

The firstsubgroup of each group $\mathrm{A}_{1}$ and $\mathrm{B}_{1}$ the obturating material was removed using Reciproc file \#40, .06 taper until removal of the obturating material to the full working length(determined using $\mathrm{k}$ file \#10 introduced inside the canal until seen flushed to the apical foramen). The Reciproc instrument was introduced inside the root canal in 3 in-and-out movements with an amplitude of approximately $3 \mathrm{~mm}$. Apical pressure was applied with gentle movements against the root canal walls, as recommended by the manufacturer. As the instrument advanced inside the root canal, it was removed and cleaned with sterile gauze. This procedure was repeated until the instrument reached the full working length. The Reciproc instrument designed for single use, and it was used only in one root canal and was then discarded.

The second subgroup of each group $A_{2}$ and $B_{2}$ the obturating material was removed from the cervical and middle thirds by Gates-Glidden \# 4, 3, 2 at speed 1000 rpm of micro motor machine followed by Hedstrom files (H-file) for the apical third with successive sizes 25,30,35,40 in a circumferential quarter-turn push pull filing motion to remove obturating materials along the whole working length.

The first class of each subgroup $\left(A_{1 a}, A_{2 a}, B_{1 a}\right.$ and $\left.B_{2 a}\right)$ the obturating material was removed using the removal systems as mentioned before in-combination with chloroform as a solvent. Few drops $(0.1 \mathrm{ml})$ of solvent (chloroform) were situated on obturation material to soften the material.

The second class of each subgroup $\left(A_{1 b}, A_{2 b}, B_{1 b}\right.$ and $\left.B_{2 b}\right)$ the obturating material was removed using the removal systems as mentioned before without using any solvent.

During re-instrumentation, every canal was irrigated with $1 \mathrm{ml}$ of freshly prepared $2.5 \%$ sodium hypochlorite after each file used.

The instruments were cleaned frequently and removal was seemed finished where no root obturating material covering the instruments. In addition, the irrigating solution seemed clear of debris. 
Environmental Scanning Electron Microscope evaluation of the canal walls cleanliness:

Preparing of grooves parallel to the long axis on the buccal and lingual surfaces of all the teeth were cut into two halves using diamond disks then splitting completed using chisel. The canal was evaluated cervical, middle, and apical thirds from coronal to apical. Each third was visualized separately using the aid of the Scanning Electron Microscope (SEM) (SEM Model Quanta 250 FEG, FEI Company, Netherlands).

The mean scores in each retreatment group were assessed for each canal level by using modified semi-quantities visual criterion with similar to that described by Madison and Hokett [11] then compared by Friedman two-way ANOVA. The significance level $(\mathrm{P} \leq 0.05)$. The correlation between the scores from the whole canals, the obturating system, and the method of retreatment (Reciprocating or manual) with or without solvent were also analyzed by Pearson's correlation.

Evaluation scales used were

- $\quad$ Score 0: None to slight presence of remnant (0-30\%)

- $\quad$ Score 1: Moderate presence of remnant (30-70\%)

- $\quad$ Score 2: Severe retreatment remnants (70-100 \%), respectively.

\section{Results}

Using the statistical two-way ANOVA test, the scores from the whole canals, the obturating system, and the method of retreatment (Reciproc or manual) with or without solvent were analyzed.
Remnant of obturating material of the canals was evaluated using Environmental Scanning Electron Microscope (ESEM). The recorded data were tabulated and statistically analyzed by using Friedman two-way ANOVA $(\mathrm{P} \leq 0.05)$

Comparison of mean values percentage of the two obturating systems removed by Reciproc or manual retreatment with solvent at cervical, middle and apical regions.

Real-Seal SE obturating system, when removed by Reciproc system $\left(A_{1 \mathrm{a}}\right)$ recorded lower remnants mean values percentage than on removal by manual instrument $\left(\mathrm{A}_{2 \mathrm{a}}\right)$ as demonstrated in table 1 and Figure 1, 2, 3. While, Gutta-percha obturating system, when removed by Reciproc system $\left(\mathrm{B}_{1 \mathrm{a}}\right)$ recorded statistically lower remnant value percentage than on removal by manual instrument $\left(\mathrm{B}_{2 \mathrm{a}}\right)$ as demonstrated in table 1 and Figure 1, 4, 5 .

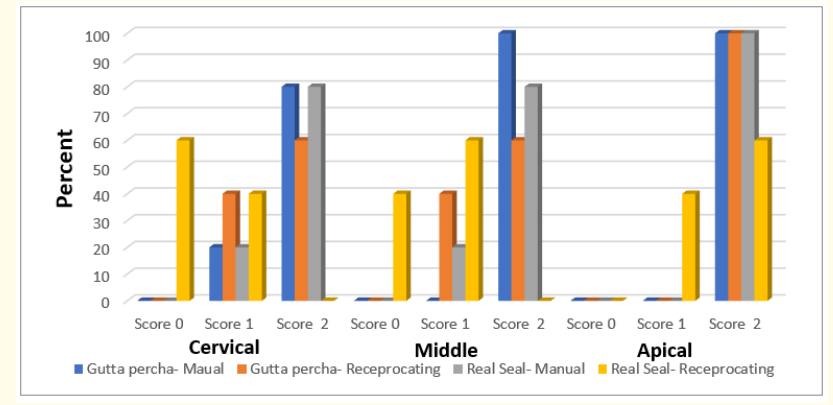

Figure 1: Comparison of remnant scoring percentage of two obturating systems removed by Reciproc or manual retreatment with solvent at cervical, middle and apical regions.

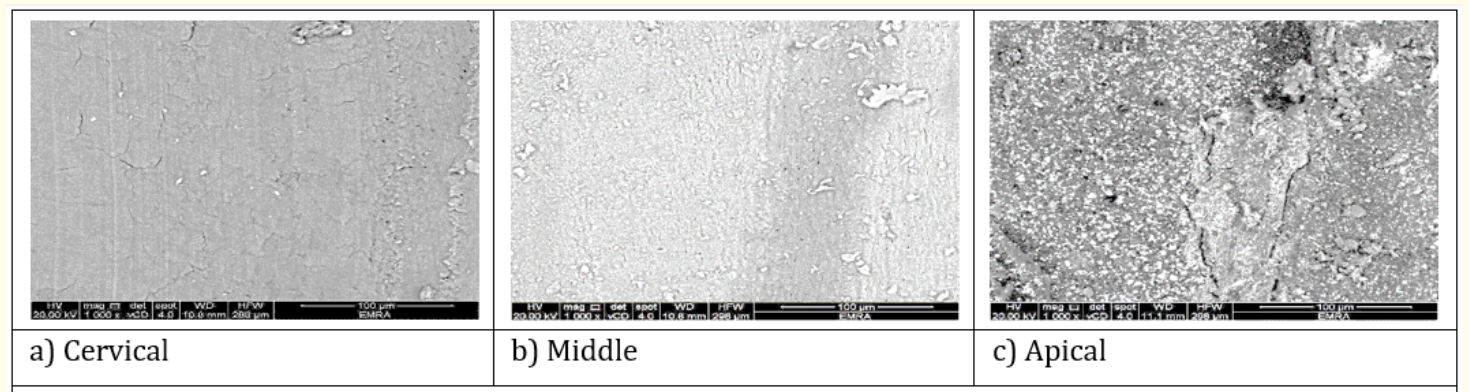

Figure 2: Scanning Electron Microscopy photographs

(X 1000) showing Real-Seal SE remnant distribution over root canal surface removed by Reciproc with using solvent $\left(\mathrm{A}_{1 \mathrm{a}}\right)$.

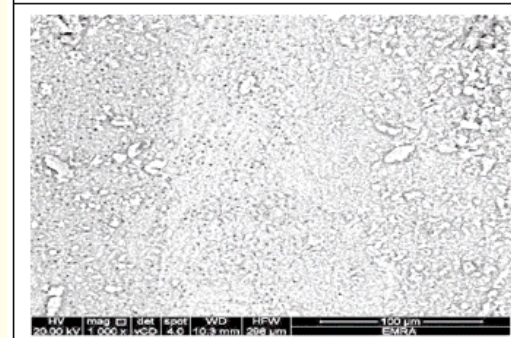

a) Cervical

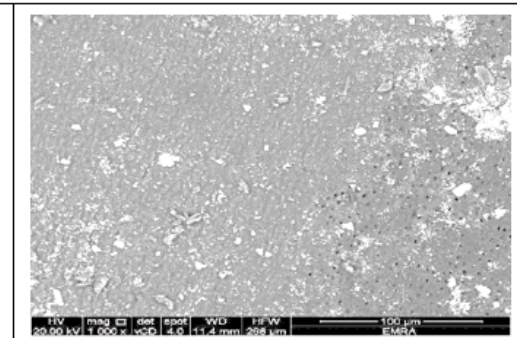

b) Middle

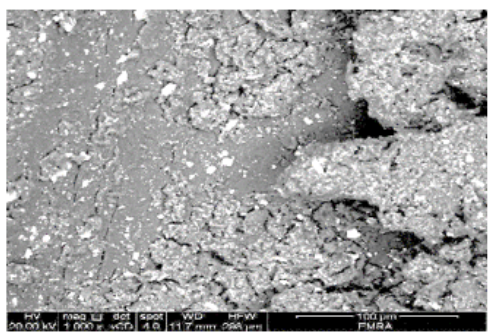

c) Apical

Figure 3: Scanning Electron Microscopy photographs

(X 1000) showing Real-Seal SE remnant distribution over root canal surface removed by manual method using solvent $\left(A_{2 \mathrm{a}}\right)$. 


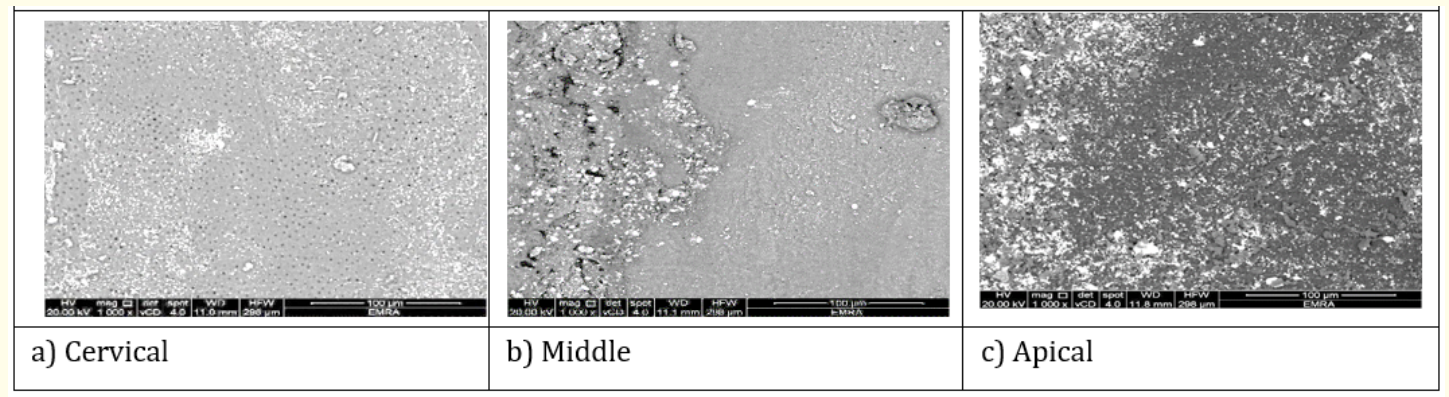

Figure 4: Scanning Electron Microscopy photograph (X 1000) showing gutta-percha remnant distribution over root canal surface removed by Reciproc using solvent, $\left(\mathrm{B}_{1 \mathrm{a}}\right)$.

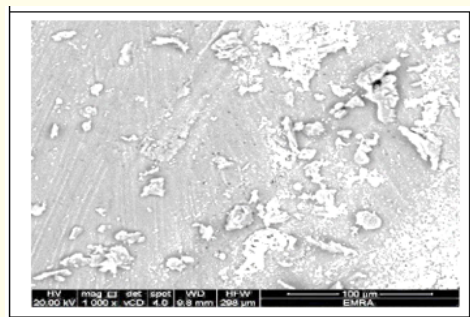

a) Cervical

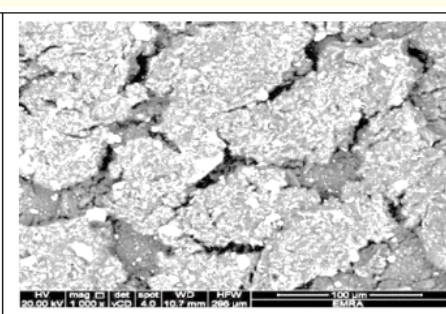

b) Middle

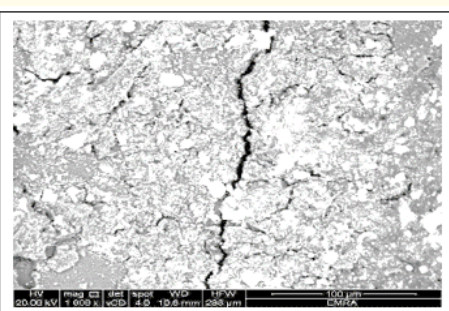

c) Apical

Figure 5: Scanning Electron Microscopy photographs

(X 1000) showing gutta-percha remnant distribution over root canal surface removed by manual method using solvent $\left(B_{2 \mathrm{a}}\right)$.

\begin{tabular}{|c|c|c|c|c|c|c|c|c|c|}
\hline \multirow{3}{*}{ Surface } & \multirow{3}{*}{ Scoring } & \multicolumn{4}{|c|}{ Real-Seal SE } & \multicolumn{4}{|c|}{ Gutta-percha } \\
\hline & & \multicolumn{2}{|c|}{ Reciprocating } & \multicolumn{2}{|c|}{ Manual } & \multicolumn{2}{|c|}{ Reciprocating } & \multicolumn{2}{|c|}{ Manual } \\
\hline & & No & $\%$ & No & $\%$ & No & & No & \\
\hline \multirow[t]{5}{*}{ Cervical } & Score 0 & 6 & 60 & 0 & 0 & 0 & 0 & 0 & 0 \\
\hline & Score 1 & 4 & 40 & 2 & 20 & 4 & 40 & 2 & 20 \\
\hline & Score 2 & 0 & 0 & 8 & 80 & 6 & 60 & 8 & 80 \\
\hline & Total & 10 & $100 \%$ & 10 & $100 \%$ & 10 & $100 \%$ & 10 & $100 \%$ \\
\hline & Statistics & \multicolumn{4}{|c|}{ Highly significant } & \multicolumn{4}{|c|}{ Significant } \\
\hline \multirow[t]{5}{*}{ Middle } & Score 0 & 4 & 40 & 0 & 0 & 0 & 0 & 0 & 0 \\
\hline & Score 1 & 6 & 60 & 2 & 20 & 4 & 40 & 0 & 0 \\
\hline & Score 2 & 0 & 0 & 8 & 80 & 6 & 60 & 10 & 100 \\
\hline & Total & 10 & $100 \%$ & 10 & $100 \%$ & 10 & $100 \%$ & 10 & $100 \%$ \\
\hline & Statistics & \multicolumn{4}{|c|}{ Highly significant } & \multicolumn{4}{|c|}{ Significant } \\
\hline \multirow[t]{5}{*}{ Apical } & Score 0 & 0 & 0 & 0 & 0 & 0 & 0 & 0 & 0 \\
\hline & Score 1 & 4 & 40 & 0 & 0 & 0 & 0 & 0 & 0 \\
\hline & Score 2 & 6 & 60 & 10 & 100 & 10 & 100 & 10 & 100 \\
\hline & Total & 10 & $100 \%$ & 10 & $100 \%$ & 10 & $100 \%$ & 10 & $100 \%$ \\
\hline & Statistics & \multicolumn{4}{|c|}{ Significant } & \multicolumn{4}{|c|}{ Non-significant } \\
\hline
\end{tabular}

Table 1: Comparison of remnant scoring percentage of two obturating systems removed by Reciproc or manual retreatment with solvent at cervical, middle and apical regions.

*The difference between variables was statistically significant as indicated by multi-factorial ANOVA test $(p<0.05)$. 


\begin{tabular}{|c|c|c|c|c|c|c|c|c|c|}
\hline \multirow{3}{*}{ Surface } & \multirow{3}{*}{ Scoring } & \multicolumn{4}{|c|}{ Real Seal SE } & \multicolumn{4}{|c|}{ Gutta-percha } \\
\hline & & \multicolumn{2}{|c|}{ Reciprocating } & \multicolumn{2}{|c|}{ Manual } & \multicolumn{2}{|c|}{ Reciprocating } & \multicolumn{2}{|c|}{ Manual } \\
\hline & & No & $\%$ & No & $\%$ & No & $\%$ & No & $\%$ \\
\hline \multirow[t]{5}{*}{ Cervical } & Score 0 & 6 & 60 & 4 & 40 & 8 & 80 & 2 & 20 \\
\hline & Score 1 & 4 & 40 & 6 & 60 & 2 & 20 & 8 & 80 \\
\hline & Score 2 & 0 & 0 & 0 & 0 & 0 & 0 & 0 & 0 \\
\hline & Total & 10 & $100 \%$ & 10 & $100 \%$ & 10 & $100 \%$ & 10 & $100 \%$ \\
\hline & Statistics & \multicolumn{4}{|c|}{ Non-significant } & \multicolumn{4}{|c|}{ Significant } \\
\hline \multirow[t]{5}{*}{ Middle } & Score 0 & 4 & 40 & 0 & 0 & 4 & 40 & 0 & 0 \\
\hline & Score 1 & 6 & 60 & 8 & 80 & 6 & 60 & 6 & 60 \\
\hline & Score 2 & 0 & 0 & 2 & 20 & 0 & 0 & 4 & 40 \\
\hline & Total & 10 & $100 \%$ & 10 & $100 \%$ & 10 & $100 \%$ & 10 & $100 \%$ \\
\hline & Statistics & \multicolumn{4}{|c|}{ Highly significant } & \multicolumn{4}{|c|}{ Highly significant } \\
\hline \multirow[t]{5}{*}{ Apical } & Score 0 & 2 & 20 & 0 & 0 & 4 & 40 & 0 & 0 \\
\hline & Score 1 & 8 & 80 & 2 & 20 & 6 & 60 & 2 & 20 \\
\hline & Score 2 & 0 & 0 & 8 & 80 & 0 & 0 & 8 & 80 \\
\hline & Total & 10 & $100 \%$ & 10 & $100 \%$ & 10 & $100 \%$ & 10 & $100 \%$ \\
\hline & Statistics & \multicolumn{4}{|c|}{ Highly significant } & \multicolumn{4}{|c|}{ Highly significant } \\
\hline
\end{tabular}

Table 2: Comparison of remnant scoring percentage of two obturating systems removed by Reciproc or manual retreatment without solvent at cervical, middle and apical regions.

*The difference between variables was statistically significant as indicated by multi-factorial ANOVA test $(p<0.05)$

Comparison of mean values percentage of the two obturating systems removed by Reciproc or manual retreatment without solvent at cervical, middle and apical regions.

Real-Seal SE obturating system, when removed by Reciproc system $\left(\mathrm{A}_{1 \mathrm{~b}}\right)$ recorded lower remnants mean values percentage than on removal by manual instrument $\left(A_{2 b}\right)$ as demonstrated in table (2) and Figure 6, 7, 8. While Gutta-percha obturating system, when removed by Reciproc system $\left(\mathrm{B}_{1 \mathrm{~b}}\right)$ recorded statistically lower remnant value percentage than on removal by manual instrument $\left(\mathrm{B}_{2 \mathrm{~b}}\right)$ as demonstrated in table (2) and Figure 6, 9, 10 .

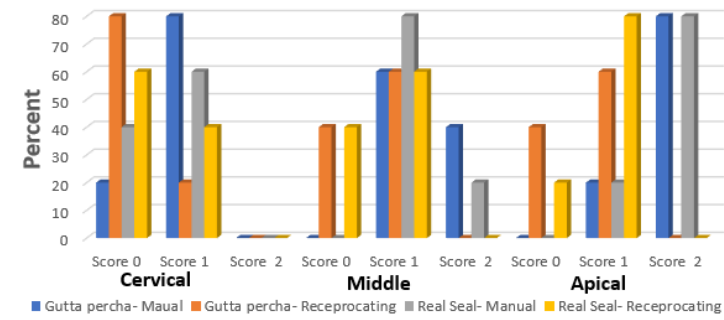

Figure 6: Comparison of remnant scoring percentage of two obturating systems removed by Reciproc or manual retreatment without solvent at cervical, middle and apical regions.

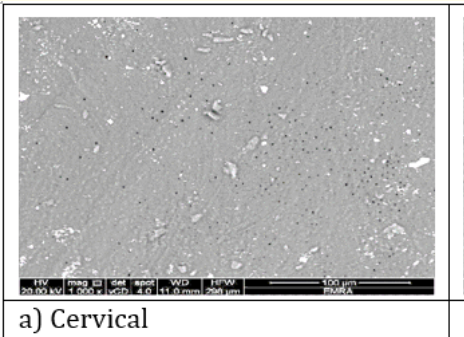

a) Cervical

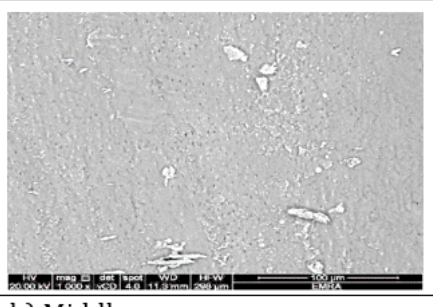

b) Middle

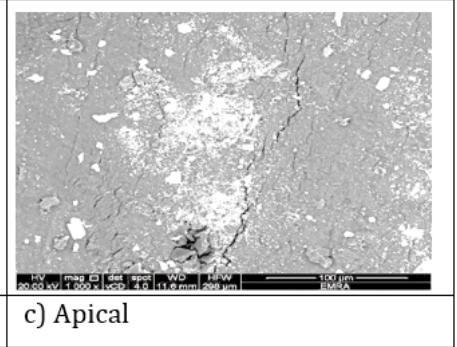

c) Apical

Figure 7: Scanning Electron Microscopy photographs (X 1000) showing Real-Seal SE remnant distribution over root canal surface removed by Reciproc without using solvent $\left(\mathrm{A}_{1 \mathrm{~b}}\right)$.

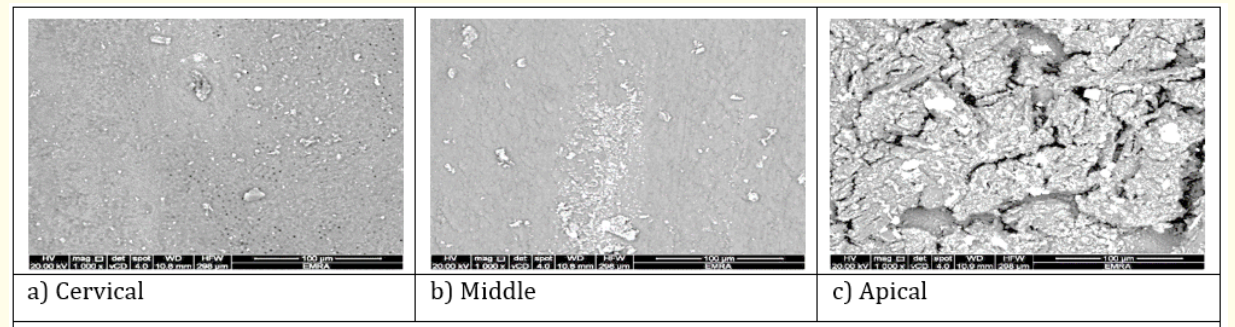

Figure 8: Scanning Electron Microscopy photographs (X 1000) showing Real-Seal SE remnant distribution over root canal surface removed by manual method without using solvent $\left(A_{2 b}\right)$. 


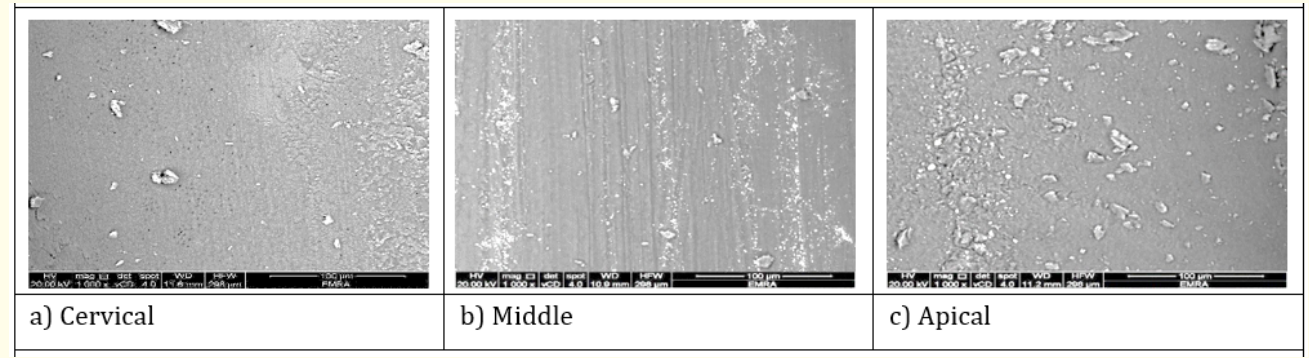

Figure 9: Scanning Electron Microscopy photographs (X 1000) showing gutta-percha remnant distribution over root canal surface removed by Reciproc without using solvent $\left(\mathrm{B}_{1 \mathrm{~b}}\right)$.

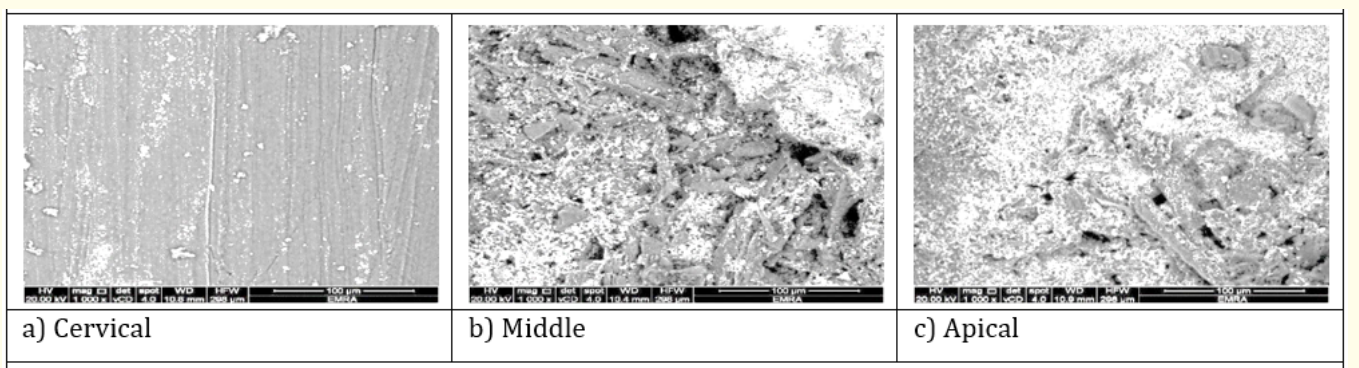

Figure 10: Scanning Electron Microscopy photographs (X 1000) showing gutta-percha remnant distribution over root canal surface removed by manual method without using solvent $\left(\mathrm{B}_{2 \mathrm{~b}}\right)$.

\section{Discussion}

The success of root canal treatment gained by obturate the prepared root canal space adequately [12]. However, in certain clinical situations such as endodontic retreatment, they should be easily removed [13].

Therefore, there was continuous developing new systems that facilitate the removal of the obturating materials. The rotary systems are actually today in endodontic retreatment [14].

In the current study, Reciproc system used for root canal retreatment using motor-driven $\mathrm{NiTi}$ instrument. These instruments are constructed of M-wire NiTi alloy, which approaches more resistance to cyclic fatigue and greater flexibility than the conventional NiTi instruments. On the other hand, the Reciproc system not first fabricated for root canal retreatment but the specific design of the instruments, in addition to reciprocating motion, can be potentially valuable for the obturating material removal [15].

Many reasons weaken resin-dentin adhesion in the root canal system. Ineffective EDTA conditioning in the deepest part along the whole surface of the root canal walls [16]. Using of sodium hypochlorite that may harmfully affect bond strength and the incidence of un-instrumented areas that may be critical for adhesion. RealSeal SE, that combines an etchant, a primer, and a sealer into an all-in-one self-etching [17]. As the etching ability of these sealers is sufficient to uncover and activate matrix metalloproteinases (MMPs) which adversely affect bonding to dentine. The thin hybrid layers created by these sealers may be susceptible to MMP-induced degradation. Dental adhesives obtain their adhesion by flowing into the spaces between adjacent collagen fibrils significant inhibition of dentin matrix-bound MMPs by 17\% EDTA within $1 \mathrm{~min}$. This may help minimize hybrid layer degradation following resin-dentin bonding procedures within the root canal system [18]. That may be clarify why it has been stated that Real-Seal displayed less adhesion to dentin and removed easier compared with gutta-percha and traditional resin sealer $[13,19,20]$.

In our study, regardless to obturating material or instrument or region, chloroform when used as a solvent showed less efficacy than without using it and this is was statistically significant. This may be due to the solvents ability to soften obturation materials and modify its contents to a viscous and highly adhesive material resulted in a filmy appearance on the canal walls and compacted into dentinal tubules. That makes it more difficult to remove. So using solvents seems to complicate rather than facilitate the filling removal [21-25]. Although, using Gates-Glidden drill was better for straight canals [20].

In our study, with or without application of solvent regardless to obturation or instrument, apical region recorded highest remnant mean value followed by middle region while the lowest mean value recorded cervically, and this was statistically significant. This may be due to that the apical portion is the narrowest and deepest part of the canal and the most difficult area to be reached with instruments and irrigating solutions and during instrumentation the remnants and debris pushed and accumulated apically [26]. 


\section{Conclusion}

Reciproc system as retreatment instrument give the best result than manual instruments in removing both obturating material used (Real-Seal SE system and Gutta-Percha) and this was statistically significant.

Without using solvent give the best result than using solvent in removing both obturating material used (Real-Seal SE system and Gutta-Percha) and this was statistically significant.

Apical region recorded highest debris mean value followed by middle region while the lowest mean value recorded cervically and this was statistically significant.

\section{Bibliography}

1. Akbar I. "Radiographic study of the problems and failures of endodontic treatment". International Journal of Health Sciences 9.2 (2015): 111-118.

2. Tabassum S and Khan FR. "Failure of endodontic treatment: The usual suspects". European Journal of Dentistry 10.1 (2016): 144-147.

3. Kanaparthy A and Kanaparthy R. "The comparative efficacy of different files in the removal of different sealers in simulated root canal retreatment- An In-vitro Study". Journal of Clinical and Diagnostic Research 10.5 (2016):130-133

4. Bergenholtz G., et al. "Retreatment of endodontic fillings". Scandinavian Journal of Dental Research 87 (2001): 217-224.

5. Pawińska M., et al. "New technology in endodontics- the Resilon-Epiphany system for obturation of root canals". Advances in Medical Science 51.1 (2006): 154-157.

6. Hassanloo A., et al. "Retreatment efficacy of the Epiphany soft resin obturation system". International Endodontic Journal 40.8 (2007): 633-643.

7. Khedmat S., et al. "Efficacy of ProTaper and Mtwo Retreatment Files in Removal of Gutta-percha and GuttaFlow from Root Canals". Iranian Endodontic Journal 11.3 (2016): 184-187.

8. Capar ID., et al. "Effectiveness of ProTaper Universal retreatment instruments used with rotary or reciprocating adaptive motion in the removal of root canal filling material". International Endodontic Journal 48.1 (2015): 79-83.
9. Oyama KO., et al. "In vitro study of effect of solvent on root canal retreatment". Brazilian Dental Journal 13.3 (2002): 208211.

10. Müller GG., et al. "Efficacy of an organic solvent and ultrasound for filling material removal". Brazilian Dental Journal 24.6 (2013): 585-590.

11. Madison JG and Hokett SD. "The effects of different tetracyclines on the dentin root surface of instrumented, periodontally involved human teeth: a comparative scanning electron microscope study". Journal of Periodontology 68.8 (1997): 739-745.

12. Epley SR., et al. "Completeness of root canal obturations: Epiphany techniques versus gutta-percha techniques". Journal of Endodontics 32.6 (2006): 541-544.

13. Soares C., et al. "Comparison of Endodontic Retreatment in Teeth Obturated With Resilon or Gutta-Percha: A Review of Literature". Iranian Endodontic Journal 10.4 (2015): 221-225.

14. Ahlquist M., et al. "The effectiveness of manual and rotary techniques in the cleaning of root canals: a scanning electron microscopy study". International Endodontic Journal 34.7 (2001): 533-537.

15. De Souza PF., et al. "Root canal retreatment using reciprocating and continuous rotary nickel-titanium instruments". European Journal of Dentistry 9.2 (2015): 234-239.

16. Zarei M., et al. "An In-Vitro Evaluation of Sealing Ability of Real Seal Using Fluid Filtration". Iranian Endodontic Journal 2.1 (2007): 11-14.

17. Lawson MS., et al. "Resistance of a 4-META-containing, methacrylate-based sealer to dislocation in root canals". Journal of Endodontics 34.7 (2008): 833-837.

18. Kim YK., et al. "Critical review of methacrylates resin-based root canal sealers". Journal of Endodontics 36.3 (2010): $383-$ 399

19. Ezzie E, et al. "Efficacy of retreatment techniques for a resinbased root canal obturation material". Journal of Endodontics 32.4 (2006): 341-344.

20. Bodrumlu E., et al. "Efficacy of 3 techniques in removing root canal filling material”. Journal Canadian Dental Association 74.8 (2008): 721. 
21. Sae-Lim V., et al. "Effectiveness of Profile .04 taper rotary instruments in endodontic retreatment". Journal of Endodontics 26.2 (2000): 100-104.

22. Kfir A., et al. "The efficacy of five techniques for removing root filling material: microscopic versus radiographic evaluation". International Endodontic Journal 45.1 (2012): 35-41.

23. Das S., et al. "Comparative evaluation of three different rotary instrumentation systems for removal of gutta-percha from root canal during endodontic retreatment: An in vitro study". Journal of Conservative Dentistry 20.5 (2017): 311-316.

24. Bhagavaldas MC., et al. "Efficacy of two rotary retreatment systems in removing Gutta-percha and sealer during endodontic retreatment with or without solvent: A comparative in vitro study". Journal of Conservative Dentistry 20.1 (2017): 12-16.

25. Dadresanfar B., et al. "Efficacy of two rotary systems in removing gutta-percha and sealer from the root canal walls". Iranian Endodontic Journal 6.2 (2011): 69-73.

26. Schirrmeister JF., et al. "Effectiveness of hand and rotary instrumentation for removing a new synthetic polymer-based root canal obturation 185 material (Epiphany) during retreatment". International Endodontic Journal 39.2 (2006):150-156.

\section{Volume 3 Issue 9 September 2019}

(c) All rights are reserved by Hayam Y Hassan., et al. 